\title{
Analysis of the Relationship Between Modeling and Decoration in Ceramic Design
}

\author{
Liu Lei, Zhao Shouli \\ College of Technology and Art, Jingdezhen Ceramic Institute
}

Key words: Ceramic Modeling; Ceramic Art; Decoration

\begin{abstract}
Archaeologists infer from the fragments of ancient pottery found in the Wannian Xianren Cave in Jiangxi that pottery has a history of nearly 10,000 years. From the development of ancient ceramics to modern artistic ceramics, there has been a very long development process, such as the development process of Jingdezhen ceramics, which has a history of as many as 1,000 years. There are obvious differences between ancient ceramic ware and modern ceramic ware in terms of ware type, molding, color painting, manufacturing process or firing process. Ceramic artworks include the container shape of ceramic matrix and decorative patterns. From ancient times to present, daily ceramics and artistic ceramics almost all have pattern decoration. Apart from a very small amount of white porcelain, there is also colored glazed porcelain as another process form of decoration. Therefore, we will discuss the relationship between modeling and decoration in ceramic design.
\end{abstract}

\section{Introduction:}

When we design a ceramic artwork, we must have an overall concept and idea in mind, so as to achieve the integration and coordination of ceramic modeling and decoration. Only in this way can we achieve the expected overall effect and be called a good and successful artwork. The creative essentials of modern artistic ceramics are to make very ingenious and novel designs and layouts according to the shapes of various shapes, and to attach importance to the coordination between the shape of ceramic containers and decorative patterns. Breaking through the traditional ancient ceramic modeling form, combining with modern aesthetic concepts and modern life tastes, and decorating new container shapes through new methods, the artistic creation of ceramics is urged to show more diversified, fresher and novel development trends.

\section{Ceramic Modeling}

\subsection{Ancient Ceramic Modeling}

At first, the ceramics invented and created by ancestors were only used as containers for drinking water and storage. However, with thousands of years of historical development, our ceramic artists have created more strange shapes and more colorful decorative images. In ancient China, porcelain has always been based on daily-use porcelain, supplemented by decorative porcelain. According to historical records, China's Song Dynasty already had more than 100 types of ceramic ware. By the Yuan Dynasty, more than 100 types of ceramic ware had been added. By the Qing Dynasty, Jingdezhen's ceramic ware had become very prosperous, there were nearly a thousand types of ceramic ware alone. Among these ceramic models, Song Dynasty porcelain has smooth and straight lines, and even the turning shapes have different feelings. The blue-and-white porcelain and the cardinal wares of the Yuan Dynasty, not only daily-use porcelain, sacrificial porcelain, but also decorative porcelain, are gradually appearing in everyone's vision. The overall feeling of Yuan Dynasty porcelain is thick and grand. In the Ming Dynasty, blue and white porcelain and multicolored porcelain were not only magnificent dragon jars and vases, but also exquisite and beautiful small and exquisite works. During the Jiajing period of the Ming Dynasty, the emperor and ministers believed in Taoism very much, so many blue-and-white ceramics, colored glazed ceramics and multicolored porcelain decorated with Taoist patterns such as eight diagrams, tai ji diagrams and pine cranes appeared. By the time of Kangxi, Yongzheng and Qianlong in the Qing Dynasty, the emperors and ministers loved Jingdezhen ceramics very much. Therefore, the official 
wares at this time did not hesitate to spend a lot of cost and working hours in order to produce exquisite and delicate porcelain with strange shapes. In the history of ancient ceramic manufacturing, folk ceramic artists have dedicated their whole lives to ceramic manufacturing for generations. It is precisely because of the wisdom, creativity and hard work of ancient ceramic artists that Jingdezhen's brilliant achievements in the history of ceramic manufacturing have been created and a large number of outstanding works that we marvel at and appreciate have been created. Most of the molding techniques of our ancient ceramic ware were made of clay strips, clay pieces for beating, clay board connection, blank drawing and manual fabrication, etc. They have very strong characteristics of manual production.

\subsection{Modern Ceramic Modeling}

With the great demand of the people for ceramic products, the ceramic technology has gradually developed from the previous hand-made methods such as blank drawing and molding to the production methods such as blank pressing machinery and grouting molding. The production of daily-use porcelain has enjoyed a prosperous development for nearly 40 years, and collectors are also very fond of artistic ceramics. In the middle and late 20th century, due to the mutual connection between artists in the cultural activities of foreign exchange, we also introduced a batch of new and peculiar pottery shapes and production methods from the west, and incorporated these into the design and creation concept of Chinese ceramic technology, and made certain changes through our own thinking and methods, which also became the bud of avant-garde ceramic art in Jingdezhen. Modern ceramic art is inherited from traditional ceramic technology and colored drawing decoration. The excited and carefree mental state of ceramic artists in the process of making porcelain is expressed through avant-garde ceramic art works. More than 50 years ago, porcelain, which was produced by pressing machines and injection molding and was liked by the public, has gradually been abandoned by the public. The manual process has become the main artistic form of modern porcelain modeling. On the mud tyre which has been drawn and formed, the bottle mouth with different shapes is made by hand along the dry and non-wet mud bottle edge, or the complete mud tyre is intentionally broken to destroy the edge and form natural gaps, cracks and mouth edges.

\section{Decorative Design of Ceramics}

With the development of science and technology and the progress of modern civilization, foreign advanced designs and technologies have been introduced into China and reformed. The ceramic firing process has undergone visible changes in specifications, shapes, varieties and decorations. Not only can huge ceramic products be fired, but also miniature ceramic new products can be fired, which can be placed in buildings and homes for decoration and appreciation, and can also be placed in hands for viewing and playing, as well as micro-carved and micro-painted artistic porcelain that needs to be viewed through a microscope. The decoration of ceramics is painted and designed by using glaze on white porcelain. The glaze of white porcelain itself is smooth and white, and the content and form are highly unified with the proper and skillful ceramic decoration design. This beautiful picture, deep artistic conception and new technique are deeply loved by modern people.

\subsection{Picture of Ceramic Decoration Design}

The charm of artistic ceramics lies mainly in attracting people's attention through novel and wonderful pictures. The most representative is the red grape porcelain vase in the blue and white glaze made by the blue and white master Wang $\mathrm{Bu}$. In terms of composition, delicate and pretty underglaze red is used to highlight the crystal-clear grape, and its lines on square porcelain are smooth and wanton, incisively and vividly, bringing people the idyllic life of contentment, beauty and variety, and the picture is fresh and elegant.

\subsection{Artistic Conception of Ceramic Decoration Design}

A successful and beautiful artistic porcelain needs not only exquisite pictures, but also profound implication, so as to be more touching. There is an old artist whose works, whether ceramic 
paintings, Chinese paintings or ceramic art works, all interpret their new meanings in plain objects. The old artist expressed that the mood at the time of artistic creation created different artistic levels and ideas, and thus different ideas, designs and methods emerged. Sometimes inspiration comes quietly like bamboo shoots after rain.

\subsection{Techniques of Ceramic Decoration Design}

If you want to explore your own unique techniques in ceramic decoration design, so as to form a unique style of ceramic decoration painting, not only the technical form can be completed, but also need ceramic artists to have a very high understanding and talent. Ceramic artists receive different education, learn different artistic techniques, and are also divided into different artistic schools, styles and personalities, thus forming their unique artistic personalities. This is reflected in the ceramic decoration design, there are different patterns and different decoration methods. Ceramic design also requires unique ideas, so as to find a new way. Fresh and wonderful composition design, beautiful and delicate ceramic modeling and delicate and pretty picture creation have made a successful ceramic artwork.

\section{Requirements for Ceramic Modeling Design and Decoration}

\subsection{Production Requirements for Modeling Design}

The modeling design of ceramics is not only to draw a drawing, but also to consider the feasibility of our design scheme in terms of the existing raw materials and the manufacturing method of the process when designing, because we still need to implement the concrete physical products in the end. Because the production process of making porcelain is more complex, and there are many limitations, so according to the design drawings to make ceramics, we also need to understand the properties of materials, which is not a easy thing to do. It is necessary to understand the plasticity of materials, what kinds of materials are suitable to be made and what methods are used. It is also necessary to master the characteristics and performance of raw materials in making blanks, moulds and firing, so as to avoid affecting the quality of ceramics.

\subsection{The Combination of Modeling Design and Practice}

Ceramic design needs to be considered from various aspects, especially daily-use porcelain. We must first consider its practicability. If we blindly pursue aesthetic design without considering the practicality of daily-use porcelain, then it will not be welcomed by people. Therefore, in order to meet people's demand for daily-use porcelain, the modeling design of ceramics must comply with and implement its practical value. We must consider the functions used, the thickness of the porcelain body, and the size of the volume. Daily ceramic ware is a container used to store all kinds of articles. The shapes of ceramic ware are different according to the types of articles and using methods, each ceramic ware needs to consider whether it conforms to people's life and using habits in terms of shape, style, size, etc. The most useful way is to carry out investigation and study, combine with reality and sum up past experience, so as to design and create more successful and practical ceramics.

\subsection{Aesthetic Problems in Modeling Design}

After ensuring the practicability of ceramic ware, we should also consider the aesthetic feeling of its shape. Although the aesthetic feeling of ceramic ware is restricted by other factors, we should not neglect the requirement for the beauty of ceramic ware. Only in this way can it be loved and pursued by more people, and can it really stand up and become a beautiful and practical ceramic artwork. In order to produce ceramic ware with aesthetic feeling, we need to consider several aspects. First, we need to consider whether the size of ceramic ware is reasonable. In the process of producing ceramic ware, we should not only pay attention to the practicability of the capacity, but also consider whether its size is appropriate to its capacity. Secondly, when designing ceramic ware, attention should be paid to bringing people a feeling of hardness and softness. It is necessary to have practicality, avoid monotony and have ever-changing forms. Finally, it is necessary to consider 
whether the coordination between the space and the entity is appropriate. The space and the entity must correspond and coordinate with each other.

\subsection{Coordination of Modeling Design and Decoration}

The coordination between ceramic modeling design and decoration is the most important point in ceramic modeling design. Decoration is the way and method to make ceramic modeling more beautiful. Therefore, ceramic modeling decoration plays an extremely important role in ceramic modeling. Ceramic artists need to carefully arrange, think carefully, and decorate properly, so as to achieve perfect coordination and unity. In real life, the coordination and unification of ceramic modeling and decoration are generally formed through these two ways. One is that the ceramic modeling is first established, and the matching decoration contents, parts and patterns are considered through the requirements of ceramic modeling. The second is to consider the shape of ceramics and the overall arrangement between the designed decorations before the design.

\section{Concluding remarks}

Ceramic decoration and modeling are complementary and coordinated with each other. The combination of perfect ceramic modeling and decoration should be as natural and harmonious as natural melons and fruits. However, ceramics are after all artificially synthesized, and their manufacturing process is very complicated, and they need to be sintered. Therefore, an overall consideration and idea should be taken into consideration in the design, so that the decoration and modeling can achieve a coordinated and unified effect. The combination of practicality and aesthetics of ceramic ware and the mutual integration of the picture, artistic conception and technique of ceramic decoration can produce a successful and perfect ceramic artwork.

\section{References:}

[1] Xu Ying. Research on Diversified Design of Daily Ceramic Product [J]. Packaging Engineering, 2019,40(08):296-298.

[2] Wen Xue. Looking at the Development of Ceramic Appliances from the Furniture Reform in Sui, Tang and Five Dynasties[J].Ceramic Research,2018,33(06):48-50.

[3] Shen Jie. Application of Fashion Elements in Ceramic Design[J]. Chinese Ceramics,2018, 54(11):84-87.

[4] Dong Rui. Research on Decorative Art of Jingdezhen New Color Ceramics[D]. Hubei University of Technology,2018.

[5] Ouyang Linxin. Research on the Relationship between Modeling and Decoration in Ceramic Design[J].Mass Literature,2018(14):77.

[6] Fang Yu. Research on the Development of Ceramic Art Design Concept[J].Technology and Economic Guide,2018,26(21):148-149.

[7] Fu Xu. Research on the Implementation of Design and Modeling Elements of Daily Ceramics[J]. Journal of Zibo Normal College,2018(02):48-51. 